\title{
Morphology, Distribution and Functional Significance of Dendritic Cells (DCs) in the Skin of Domestic Animals
}

\author{
R. Gnanadevi ${ }^{1}$, T.A. Kannan ${ }^{2 *}$, S. Ushakumary ${ }^{1}$ and Geetha Ramesh ${ }^{1}$ \\ ${ }^{1}$ Department of Veterinary Anatomy, Madras Veterinary College, Chennai-600 007, India \\ ${ }^{2}$ Centre for Stem Cell Research and Regenerative Medicine, Madras Veterinary College, \\ Chennai-600 007, India \\ *Corresponding author
}

\section{A B S T R A C T}

In mammals, skin is the largest of the body's organs which provides an immediate and excellent barrier between the internal tissues and external environment. Dendritic cells are

\section{Keywords}

Skin, Dendritic cells, Morphology,

Distribution, Domestic animal species

Article Info

Accepted:

12 April 2018

Available Online:

10 May 2018 antigen presenting cells which regulate the immune responses. The present study, aimed to describe the morphology and distribution of dendritic cells present among the skin of cattle, buffalo, sheep and goat. Dendritic cells were stained using Osmium tetroxide solution. The dendritic cells were mostly located in the basal layer at epidermis except small ruminats wherein the cells were mostly in the dermis. Morphology of the DCs also exhibited variations between these domestic animal species. Two types of DCs namely typical dendritic cells and atypical dendritic cells were observed in this study. Both the cell types showed the presence of intra cytoplasmic birbek granules. Typical dendritic cell morphology were found to be more in buffalo skin. The number of DCs from most numerous to least in number in the present study as follows: buffalo, cattle, sheep and goat. The number of dendritic cell in the present study indicated the incidence or prevalence of skin diseases was least in buffalo followed by cattle and more incidence of skin diseases in sheep and goat.

\section{Introduction}

Skin is one of the largest organs in the body of human and animals, which acts as the primary interface with the external environment. In order to perform its protective function, mammalian skin consists of both physical and immunological barriers (Ono and Kabashima, 2016).

Dendritic cells (DCs) are a heterogeneous population of leukocytes that are critical in orchestrating immune responses in skin and also in mucosa (Manickam et al., 2007), and contain large organelles called Birbeck granules (Young et al., 2000). These cells are also known as antigen-presenting immune cells associated with squamous epithelia and mucosa. DCs were first described by Paul Langerhans, in 1868, as dendritic shaped cells, which are located in the squamous epithelia of epidermis. Later on, these cells are identified in all stratified squamous epithelium in mammals. The DCs originate from the bone 
marrow and then migrate into the epithelium to perform the function of antigen recognition and presentation. Dendritic cells (DCs) play an important role in local defence mechanisms by presenting the external antigen to $\mathrm{T}$ cells and initiate immune response by stimulating other types of immune cells (Tae-Gyun Kim et al., 2017). One of the most remarkable properties of the DCs in epidermis is the presence of characteristic cytoplasmic birbeck granules which are selectively stained with zinc iodide-osmium (ZIO) solution (Rodriguez and Caorsi, 1978).

There are plenty of works documented about the DCs in skin and other mucosa in human (Figueroa and Caorsi, 1980; Lombardi et al., 1993; de Witte et al., 2012; Shweta Jaitley and Saraswathi, 2012). However, there is paucity of literature available about the DCs in skin of domestic animals. Hence, the present study was undertaken to study distribution and morphology of DCs among the domestic animals and to correlate with the incidence of skin diseases to the extent possible.

\section{Materials and Methods}

The skin samples from cattle, buffalo, sheep and goat (six samples in each species) were collected from the local Corporation slaughter house, Chennai and were immersed in a solution of veronal-buffered zinc iodideosmium tetroxide at $\mathrm{pH} 7.4$ for 48 hours at $4^{\circ} \mathrm{C}$ in dark. The fixed tissue pieces were washed in distilled water, dehydrated in ascending grades of alcohol, cleared in xylene, and embedded in paraffin wax. Serial sections were cut and the sections were transferred to glass slides. The cut sections were deparaffinised, mounted in DPX, without counter staining and were viewed under a light microscope (Indrasingh et al., 2001). The stained sections were viewed and photomicrographs were taken using Olympus photomicroscope.

\section{Results and Discussion}

In the present study, the distribution and morphology of the dendritic cells showed variations between cattle, buffalo, sheep and goat. Based on the morphology, the dendritic cells were classified into cells showing typical dendritic cells and atypical dendritic cells (Fig. 1).

\section{Typical Dendritic cells}

These cells were polygonal in shape with both branched and unbranched cytoplasmic processes radiating away from the cell in all directions (Fig. 2). The number of cytoplasmic processes of typical dendritic cells varied among the different domestic animals. The cytoplasm showed the presence of ZIO positive granules. The amount and distribution of birbek granules in all the polygonal cells showed variations among the different species.

\section{Atypical dendritic cells}

These cells were bipolar or triangular or pyramidal in shape. The bipolar cells exhibited fibroblast-like morphology. The cytoplasmic processes were very short, branched / unbranched extending from either ends of the cells (Fig. 3). The triangular cells had three angles, of which, only one angle showed a slender unbranched cytoplasmic process while the other two angles were pointed, without cytoplasmic projections (Fig. $3)$.

The cytoplasmic processes were found to be longer than the bipolar cells. The pyramidal cells showed a smooth round apical portion and two cytoplasmic processes projecting at right angles from the basal portion of the cell (Fig. 3). The cytoplasmic processes were thicker and unbranched. All the cell types showed the presence of intra cytoplasmic birbek granules. 
Fig.1 Photomicrograph of skin of cattle showing polygonal morphology of DCs (typical dendritic cells- arrow) with more than three cytoplasmic processes and triangular shape DCs with cytoplasmic processes (non-dendritic cells-arrow heads) in Stratum basale

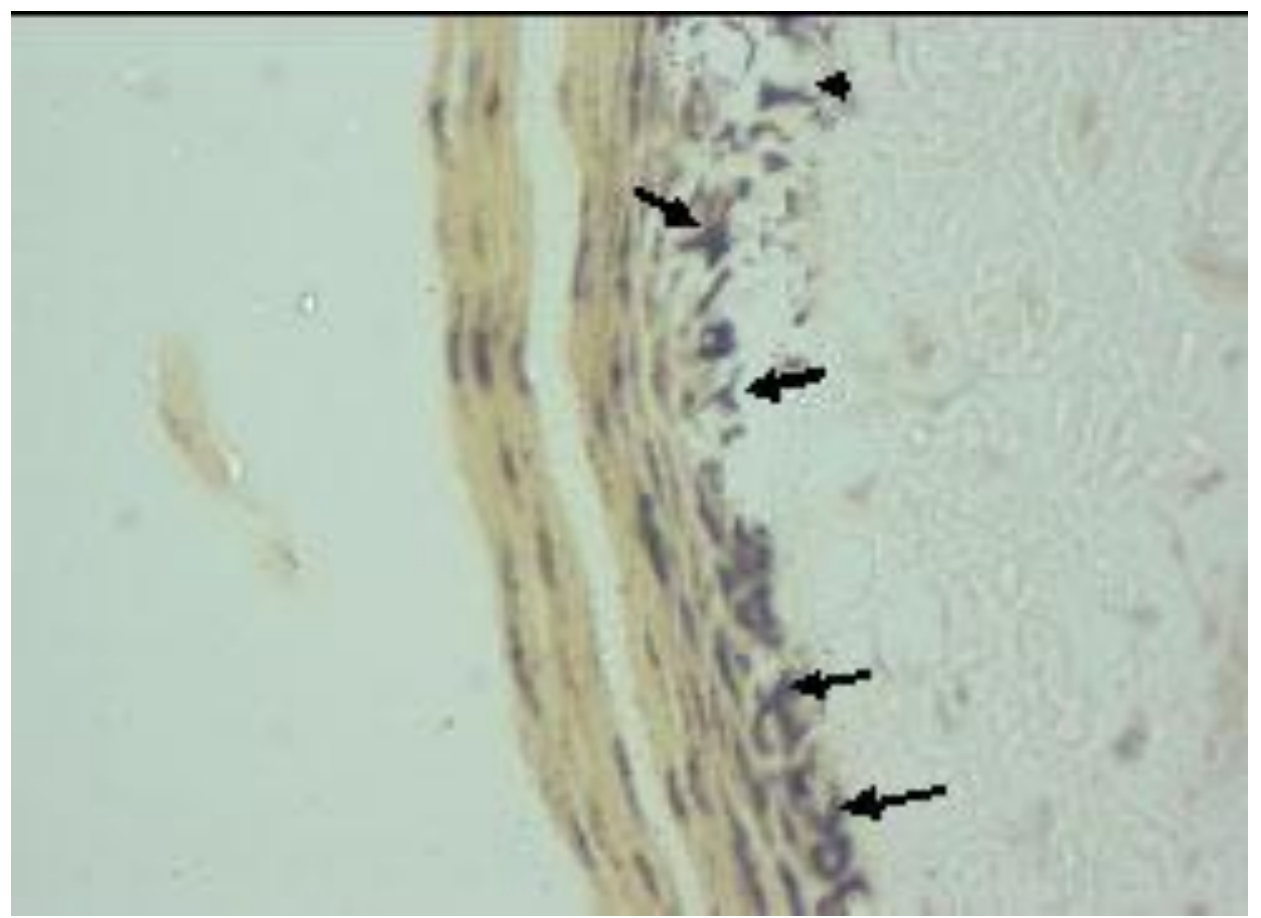

ZnO-OsO4 method x 400

Fig.2 Photomicrograph of skin of cattle showing triangular shape DCs with three cytoplasmic processes (arrow) showing distribution of birbek granules

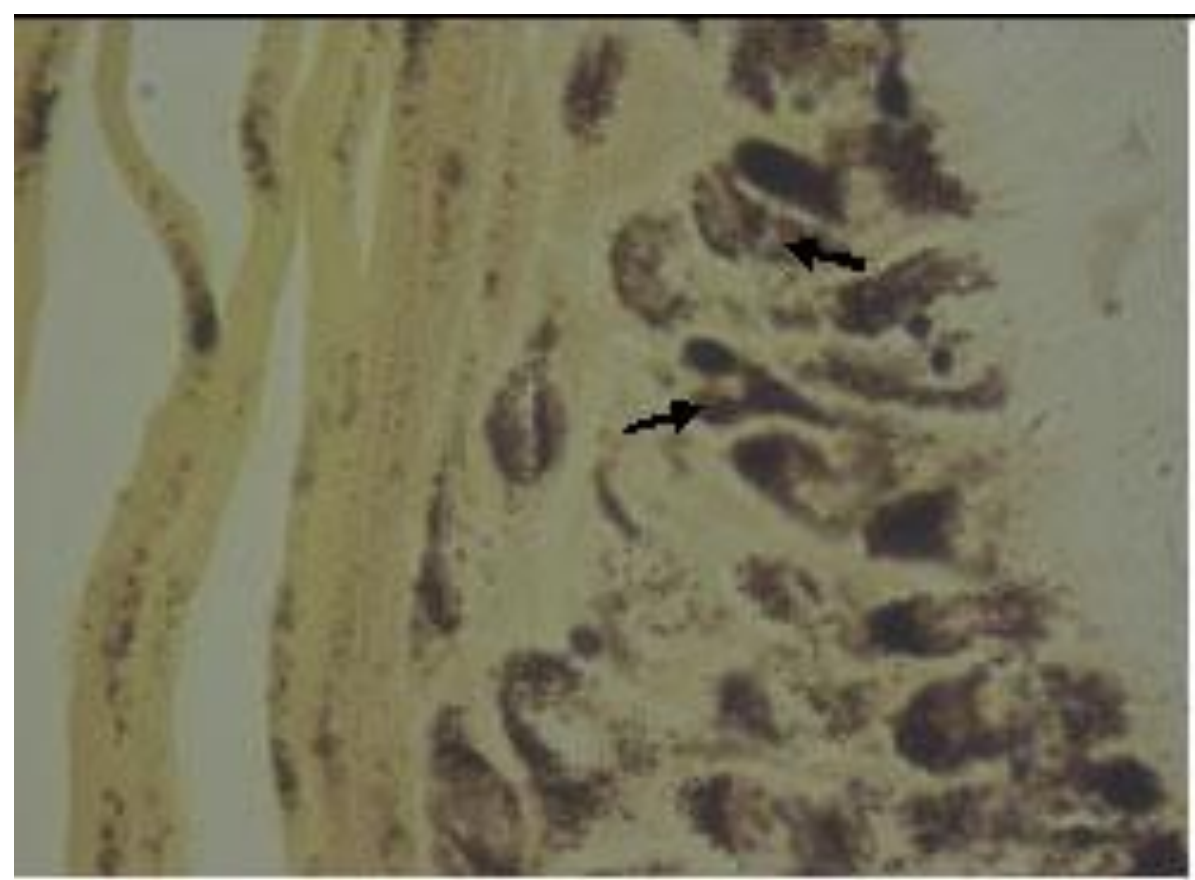

ZnO-OsO4 method x 1000 
Fig.3 Photomicrograph of skin of cattle showing non-dendritic cell morphology of bipolar (red arrow), triangular (black arrow) and pyramidal in shape (blue arrow)

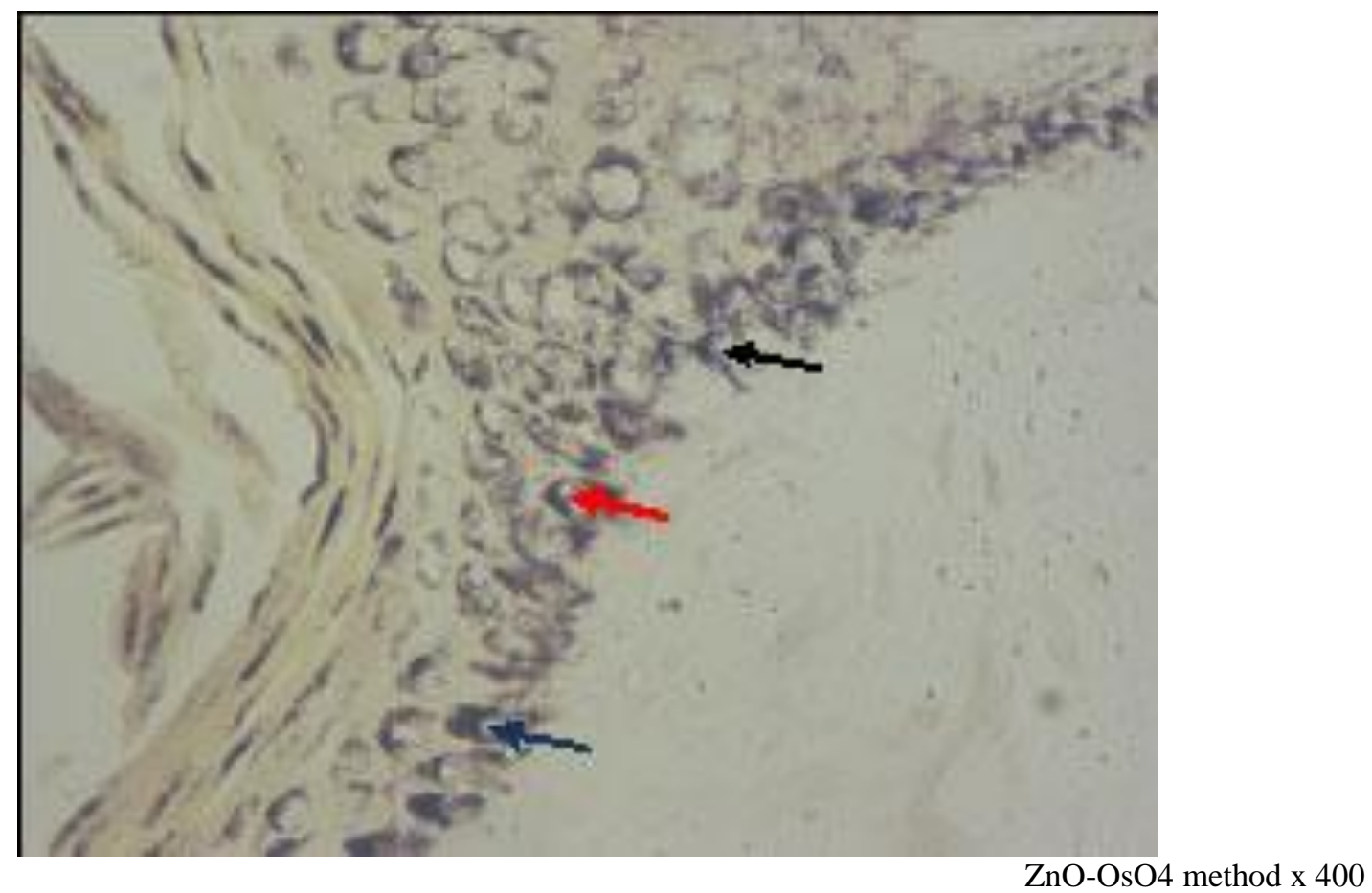

Fig.4 Photomicrograph of skin of buffalo in panoramic view showing osmium tetroxide positive cells in stratum basale (arrow)

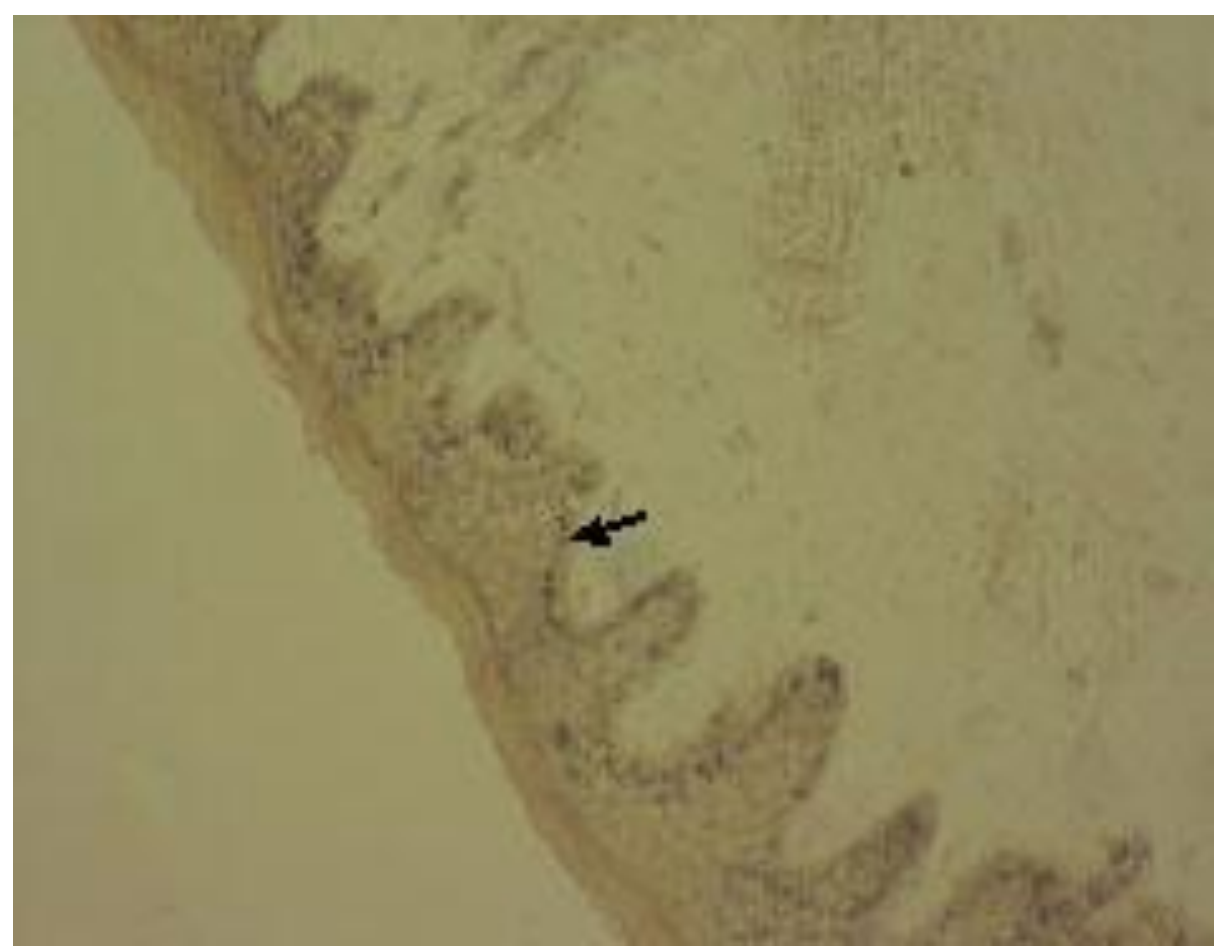


Fig.5 Photomicrograph of skin of cattle showing triangular shape DC with three cytoplasmic processes (arrow)

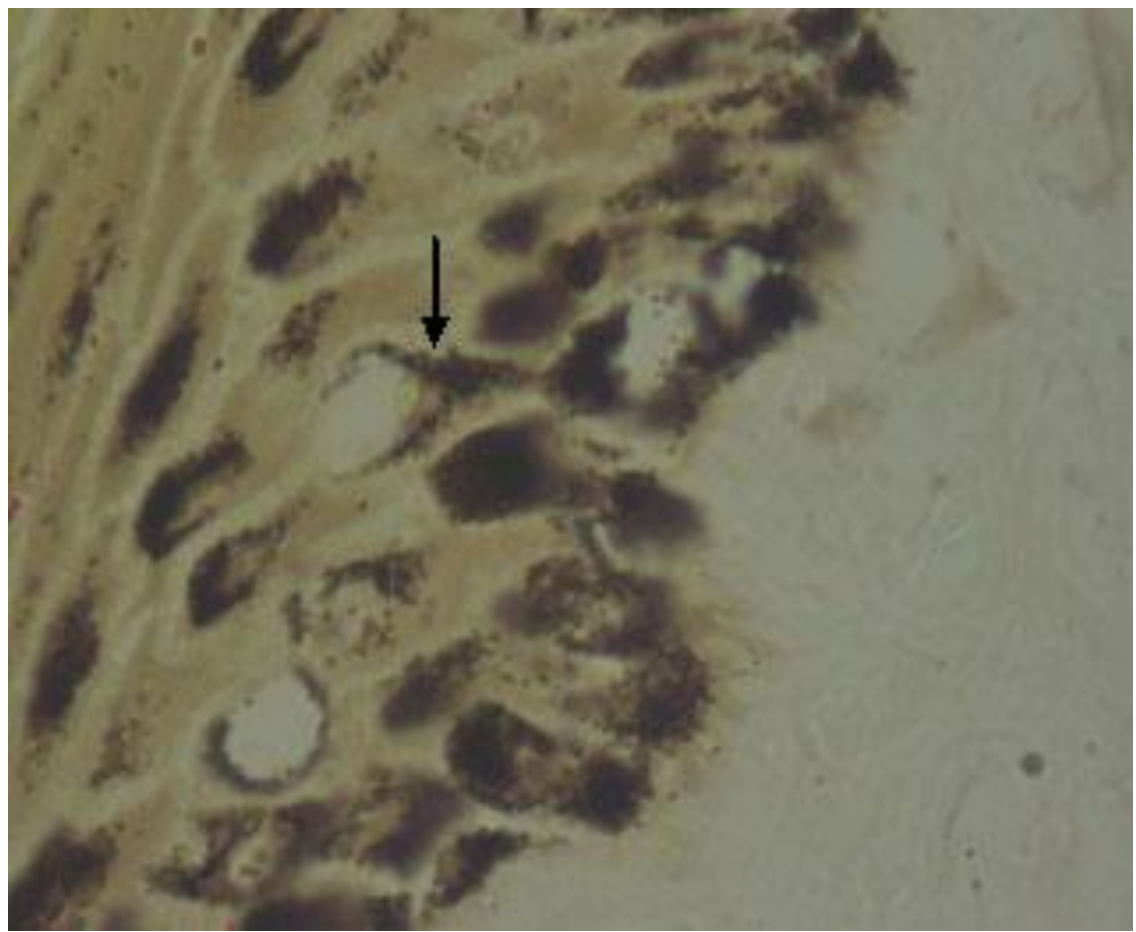

ZnO-OsO4 method x 1000

Fig.6 Photomicrograph of skin of sheep showing presence of DCs in hair follicles

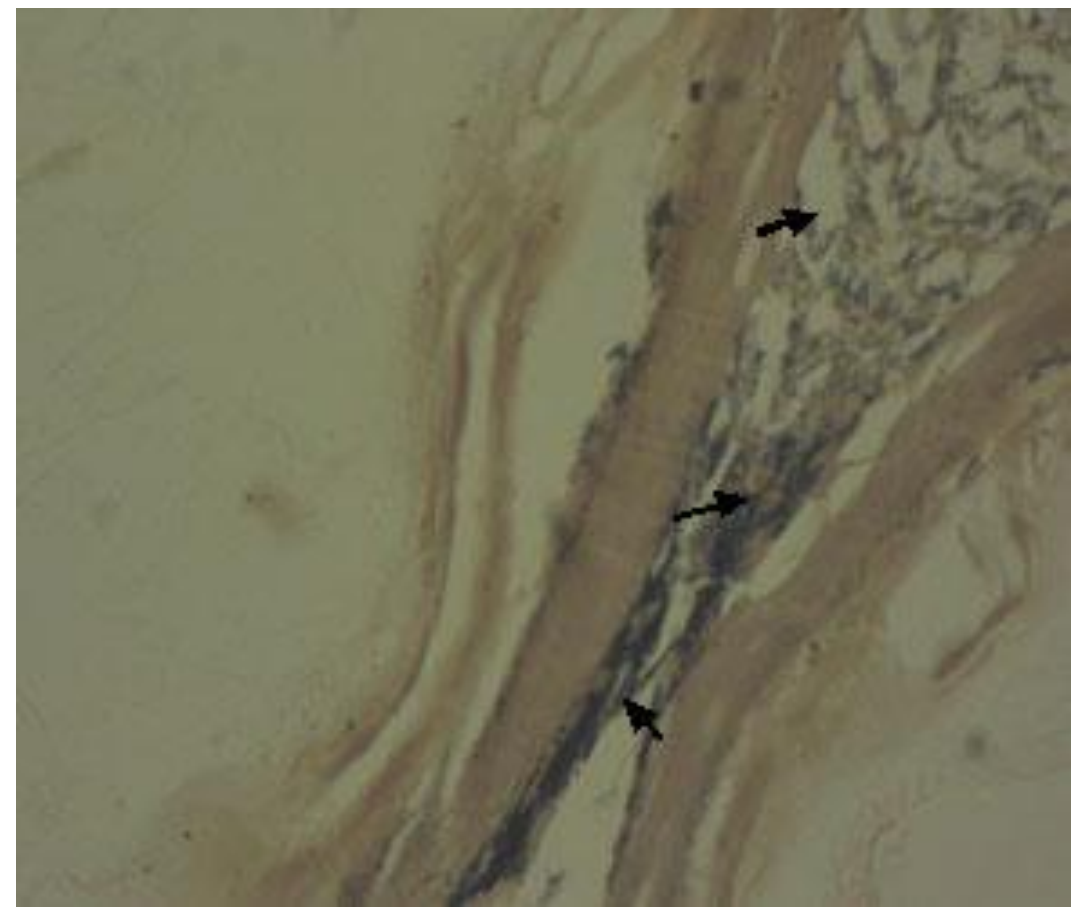

ZnO-OsO4 method x 400 
In the present study, atypical dendritic cells of various shapes were observed in the skin of all domestic animals. However, triangular and pyramidal shaped cells were found to be more in cattle, polygonal cells with typical dendritic cells morphology were found to be most numerous in buffalo skin. In sheep and goat, typical, polygonal dendritic cells were found to be more.

In the present study, the dendritic cells were found to be observed in the basal layer of epidermis in all the domestic animals (Fig. 4). However in cattle, in addition, the dendritic cells were also found in the suprabasal layer of epidermis (Fig. 5). In sheep and goat, the dendritic cells were mostly found in dermis (Fig. 6) in the vicinity of hair follicles and sweat glands.

Among the domestic animal species under this study, the dendritic cell were found to be most numerous in the skin of buffalo, more in white cattle and least in sheep and goat.

In the present study, based on morphology, the dendritic cells were classified into typical dendritic cells and atypical dendritic cells. This is similar to the finding of Figueroa and Caorsi (1980) and Rabi et al., (2014) in normal human cervix. Presence of welldeveloped cytoplasmic processes in typical dendritic cells might help them in migration of DCs after exposure to antigen to perform immunostimulatory activity.

This migration carried the antigen from the skin or mucosa to the helper $\mathrm{T}$ cells of the lymph nodes (Cutler and Jotwani, 2004). In the present study, though, the DCs were observed in the basal layer of epidermis in all the species and even in dermis in sheep and goat, the delicate dendritic processes could be observed extending to the level of stratum corneum and usually directed towards epithelial surface (De Witte et al., 2012). This arrangement made possible to contact with surface antigens that reaches the skin.

Although, the number of cytoplasmic processes varied between typical and atypical DCs in the skin of domestic animals, there won't be any difference in distribution of organelles as reported by Figueroa and Caorsi (1980) which hypothesised that both the cell types can perform immune function.

Stratified squamous keratinised epithelium which constitutes the whole epidermis is avascular structure. This may be the reason for the change in shape and size of the cells, the cells become smaller as they move towards the suprabasal layer in contrast to basal layer and in dermis.

In the present study, the dendritic cell were found to be most numerous in the skin of buffalo, more in white cattle and least in sheep and goat. Since the DCs are antigen presenting cells involved in immune function, it can be hypothesised that those species which had numerous DCs are less prone for skin diseases. This could be confirmed with the findings of Yacob et al., (2008) who examined on a total of 584 cattle, 377 sheep and 295 goats for the prevalence of skin diseases. The overall prevalence for skin diseases were $15.41 \%$ in cattle and $25 \%$ in sheep and goats. Another cross sectional study was carried out by Teshome and Derso (2015) to determine the prevalence of major skin disease with 513 cattle, 631 sheep and 152 goats. The prevalence of skin diseases in cattle, sheep and goats was found to be $27.68 \%, 42.47 \%$ and $38.12 \%$ respectively.

Based on the above findings, it was concluded that the dendritic cell population in the skin of domestic animals is directly proportional to the prevalence of skin diseases among them. DCs served as messengers between the innate and adaptive immune systems. 


\section{Conflict of interest}

The authors declare that there is no conflict of interest.

\section{References}

Cutler, C.W. and Jotwani, R. 2004. Antigen presentation and the role of dendritic cells in periodontitis. Periodontol 2000. 35: $135-57$.

De Witte, L., Nabatov, A., Pion, M., Fluitsma, D., de Jong, M.A., de Gruijl, T., Piguet, V., van Kooyk. Y. and Geijtenbeek, T.B. 2007. Langerin is a natural barrier to HIV-1 transmission by Langerhans cells. Nature Med. 13(3): 367- 371.

Figueroa, C. D. and Caorsi, I. 1980. Ultrastructural and morphometric study of the Langerbans cell in the normal human exocervix. J. Anat. 131(4):669682.

Indrasingh, I., Abraham, S. and Vettivel, S.K. 2001. Zinc iodide osmium positive cells and dendritic cells in stratified squamous epithelium of lip, tongue, and oesophagus of bonnet monkey (Macaca radiata). J Anat. Soc. India 50(1) 34-36.

Lombardi, T., Hauser, C., and BudtzJörgensen, E.1993. Langerhans cells: structure, function and role in oral pathological conditions. J Oral Pathol Med. 22:193-202.

Manickam, A., Sivanandham, M., and Tourkova, IL. 2007. Immunological role of dendritic cells in cervical cancer. Adv Exp Med Biol., 601:155-62.
Ono, S and Kabashima, K. 2016. The role of dendritic cells and macrophages in the skin immunity. Japanese J. Clin. Immunol., 39(5):448-454.

Rabi, S., Lionel, J., Indrasingh, I. 2014. Morphological Study of Dendritic Cells in Human Cervix by Zinc Iodide Osmium Method. Journal of Clinical and Diagnostic Research. 8(6): AC01AC04.

Rodriguez, E. M. and Caorsi, I. 1978. A second look at the ultrastructure of the Langerhans cell of the human epidermis. J. Ultrastruct. Res. 65: 279295.

Shweta Jaitley and Saraswathi, T.R. 2012. Pathophysiology of Langerhans cells. $J$ Oral Maxillofac Pathol. 16:239-44.

Tae-Gyun Kim, Sung Hee Kim and Min-Geol Lee. 2017. The Origin of Skin Dendritic Cell Network and Its Role in Psoriasis. Int. J. Mol. Sci., 19(42): 1-14.

Teshome, D. and Derso, S. 2015. Prevalence of Major Skin Diseases in Ruminants and its Associated Risk Factors at University of Gondar Veterinary Clinic, North West Ethiopia. J Veterinar Sci Technol., S13-002.

Yacob, H. T., Nesanet, B., and Dinka, A. 2008. Part II: Prevalences of major skin diseases in cattle, sheep and goats at Adama Veterinary Clinic, Oromia regional state, Ethiopia Revue Méd. Vét. $159,8-9,455-461$.

Young, Barbara, Heath and. John, W. 2000. Wheater's Functional Histology (4th ed.). Churchill Livingstone. 162.

\section{How to cite this article:}

Gnanadevi, R., T.A. Kannan, S. Ushakumary and Geetha Ramesh. 2018. Morphology, Distribution and Functional Significance of Dendritic Cells (DCs) in the Skin of Domestic Animals. Int.J.Curr.Microbiol.App.Sci. 7(05): 1554-1560. doi: https://doi.org/10.20546/ijcmas.2018.705.184 